Open Access

\title{
Catastrophic health expenditure and 12-month mortality associated with cancer in Southeast Asia: results from a longitudinal study in eight countries
}

The ACTION Study Group

\begin{abstract}
Background: One of the biggest obstacles to developing policies in cancer care in Southeast Asia is lack of reliable data on disease burden and economic consequences. In 2012, we instigated a study of new cancer patients in the Association of Southeast Asian Nations (ASEAN) region - the Asean CosTs In ONcology (ACTION) study - to assess the economic impact of cancer.

Methods: The ACTION study is a prospective longitudinal study of 9,513 consecutively recruited adult patients with an initial diagnosis of cancer. Twelve months after diagnosis, we recorded death and household financial catastrophe (out-of-pocket medical costs exceeding $30 \%$ of annual household income). We assessed the effect on these two outcomes of a range of socio-demographic, clinical, and economic predictors using a multinomial regression model.

Results: The mean age of participants was 52 years; $64 \%$ were women. A year after diagnosis, $29 \%$ had died, $48 \%$ experienced financial catastrophe, and just $23 \%$ were alive with no financial catastrophe. The risk of dying from cancer and facing catastrophic payments was associated with clinical variables, such as a more advanced disease stage at diagnosis, and socioeconomic status pre-diagnosis. Participants in the low income category within each country had significantly higher odds of financial catastrophe (odds ratio, 5.86; $95 \%$ confidence interval, 4.76-7.23) and death $(5.52 ; 4.34-7.02)$ than participants with high income. Those without insurance were also more likely to experience financial catastrophe $(1.27 ; 1.05-1.52)$ and die $(1.51 ; 1.21-1.88)$ than participants with insurance.

Conclusions: A cancer diagnosis in Southeast Asia is potentially disastrous, with over $75 \%$ of patients experiencing death or financial catastrophe within one year. This study adds compelling evidence to the argument for policies that improve access to care and provide adequate financial protection from the costs of illness.
\end{abstract}

\section{Background}

The Association of Southeast Asian Nations (ASEAN) region consists of ten countries - Brunei, Cambodia, Indonesia, Laos, Malaysia, Myanmar, the Philippines, Singapore, Thailand, and Vietnam - and is home to over half a billion people. The burden of cancer is increasing in the ASEAN region, due to population ageing and growth and the adoption of cancer-associated lifestyle behaviours [1]. In 2012, there were estimated to be over

Correspondence: mkimman@georgeinstitute.org.au

The George Institute for Global Health, Level 10, King George V Building, 83-117 Missenden Road, Camperdown, NSW 2050, Australia
750,000 new cases of cancer, and incidence is expected to rise to 1.3 million per year by 2030 [2]. Survival rates for most cancers are poor and quality of life is greatly impaired [2-4]. In addition to this significant disease burden, cancer can have a profound economic effect on individuals and their households, especially among the poor and under-insured [5].

Most studies examining the economic burden of cancer have, however, been conducted in high-income settings. Little is known about its economic impact in low- and middle-income settings, where the financial implication of a cancer diagnosis may not be equitable because out-ofpocket (OOP) payments are the principal means of

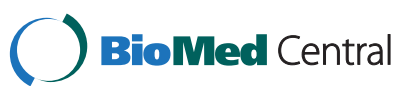


financing health care [6]. This not only relates to primary treatment, but may include long-term costs of adjuvant therapy and follow-up care [7-9]. Hence, a cancer diagnosis can quickly result in catastrophic payments for a household; that is, spending a disproportionate amount of household income on cancer treatment [10]. Furthermore, patients may be unable to continue working due to the burden of their symptoms, treatment, or side-effects, leading to poorer economic circumstances [11].

Health insurance is seen as an important means in offering households protection from catastrophic payments for illness. However, the extent of financial protection through insurance depends on which health services are covered and the level of subsidy offered. In the ASEAN region, while population coverage varies between $8 \%$ (Laos) and $100 \%$ (Malaysia), all countries including those with universal health coverage - rely heavily on OOP financing $[12,13]$.

Despite the risk of a cancer epidemic overwhelming the region, governments have been slow to react to the health consequences of socioeconomic and demographic changes. Hence, in 2011, two regional initiatives were launched to increase cancer awareness and inform priority setting. First, a series of roundtable meetings of key stakeholders and experts were organised to generate knowledge and interest through engagement with the media [14, 15]. Second, a study of new cancer patients in eight countries in the ASEAN region (Cambodia, Indonesia, Laos, Malaysia, Myanmar, the Philippines, Thailand, and Vietnam) was instigated - the Asean CosTs In ONcology (ACTION) study - to assess the economic and health impact of cancer. This paper presents the main results.

\section{Methods}

\section{Ethical approval}

The ACTION study was approved by the University of Sydney's Human Research Ethics Committee. Approvals from local institutional ethics committees and other regional or national regulatory bodies were obtained prior to the initiation of the study in all centres (Additional file 1). Written informed consent, complying with local, regional, and national requirements, was obtained from all participants prior to entry into the study.

\section{Study design}

ACTION was a prospective longitudinal study; detailed methods have been published previously [16]. In brief, patients diagnosed with a first time cancer were consecutively recruited (within 12 weeks from initial date of diagnosis) from 47 sites, including public and private hospitals and cancer centres. Patients were aged 18 years and older, aware of their cancer diagnosis, and willing to participate in follow-up interviews. Participants were interviewed (face-to-face or by telephone) at baseline, 3 , and 12 months after diagnosis. Questionnaires were translated into local languages.

\section{Baseline measures and key outcomes}

Data were collected on age, sex, marital status, country of residence, highest level of education attained, employment status, recent experience of economic hardship (whether in the previous 12 months they were unable to make any necessary household payments (for example, food, housing) or needed assistance to do so) [17], annual household income, and health insurance status. Clinical characteristics, cancer site, and cancer stage (TNM classification) were obtained from medical records. Health-related quality of life was assessed using the EuroQol (EQ-5D) [18]. Further details are given in the study protocol [16].

The primary outcome at 12 months was financial catastrophe (FC) following treatment for cancer, defined as OOP costs at 12 months equal to or exceeding $30 \%$ of annual household income $[19,20]$. OOP costs represented hospital and non-hospital health care costs which were directly incurred by patients at point of delivery and not reimbursed by insurance. Participants prospectively completed a cost diary for the duration of the study. The second key outcome was all-cause mortality. FC and death were recorded at both follow-up interviews.

\section{Statistical analyses}

Multinomial regression models were used to estimate odds ratios (ORs) and $95 \%$ confidence intervals (CIs) for death and FC, relative to being alive without experiencing FC, thus allowing for death as a competing risk to FC. Baseline characteristics considered for association with these joint outcomes were socio-demographic (age, sex, and level of education), economic (household income grouped into low (0-75\% of mean national income), middle (75-125\%), and high income (>125 \%), insurance status (yes or no), experience of economic hardship, and paid work status), and clinical (baseline health-related quality of life, cancer site - separately by sex - and cancer stage) [21]. Due to small numbers for some cancer sites, sites were grouped into body location or system: digestive/gastrointestinal; breast; gynaecological; head and neck; haematological/blood; respiratory/thoracic; and other cancers. Analyses were adjusted for age, sex, cancer stage, and geographic region, grouped as low (Cambodia, Myanmar), low-middle (Indonesia, Laos, Vietnam, the Philippines), and uppermiddle income (Thailand, Malaysia). Participants who experienced FC at 3 months, but could not be contacted at 12 months, were coded as having experienced FC at 12 months. Primary analyses were conducted on participants with complete data on outcome status at 12 months. More extreme cut-offs for household income 
groups were tested in a sensitivity analysis: low $(0-50 \%$ of mean national income); middle (50-150\%); and high income $(>150 \%)$. Furthermore, multiple imputation $(m=5)$ using predictive mean matching was carried out to impute the missing data on the outcome variables. The imputation models included the outcome variables themselves, all socio-demographic, clinical, and economic predictors examined, and country [22]. Analyses were performed using STATA, version 12.0 (Stata, College Station, TX, USA), and R, version 2.15.3 (R Foundation for Statistical Computing, Vienna, Austria).

\section{Results}

Between March 2012 and September 2013, after exclusions due to patient or doctor refusals, 9,513 patients were recruited into the study. The mean age was 52 years, $64 \%$ were women, $61 \%$ had attained at least secondary education, and $45 \%$ had some form of health insurance. The most common cancer site recorded was breast $(26 \%)$; the greatest number was recruited in Indonesia (Table 1). For patients with available data on cancer stage $(\mathrm{n}=5,159), 11 \%$ presented with stage I, $31 \%$ with stage II, $33 \%$ with stage III, and $24 \%$ with stage IV cancers. Haematological cancers were diagnosed in 825 patients (Additional file 2: Table S1).

The follow-up interviews at 3 and 12 months were completed by 7,245 (76 \%) and 5,245 (55\%) participants, respectively. At 12 months, 1,993 (29\%) participants had died. Complete outcome data (data on FC and death) were available for 6,787 participants (71 \%) (Fig. 1).

Participants with incomplete outcome data $(\mathrm{n}=2,726)$ were slightly younger (51 versus 52 years), more likely to be male (38 versus $33 \%$ ), and less likely to have a high income (17 versus $38 \%$ ), compared to those with complete outcome data (all $P$ values $<0.001$ ). There were no significant differences in other socio-demographic, clinical, or economic characteristics.

At 12 months, 3,248 participants ( $48 \%$ of those with complete outcome data) experienced FC and 1,546 (23\%) were alive and did not experience FC. Survival without FC was most frequent in participants with haematological cancer (37 \%), gynaecological cancer (27 \%), and breast cancer (26\%) (Fig. 2).

After controlling for confounding variables, women had lower odds of death (OR, 0.62; $95 \%$ CI, 0.51-0.75) than men, but sex was not significantly associated with FC, relative to the reference outcome (alive and no FC) (Table 2). Age of $>65$ years was associated with a higher odds of FC $(1.51 ; 1.17-1.94)$ and death $(2.64 ; 2.00-3.49)$, compared to age $<45$ years. Being unmarried was also associated with a higher odds of FC (1.09; 1.09-1.60) and death $(1.42 ; 1.15-1.77)$, compared to participants who were married. Having completed primary education only, compared to tertiary education, was significantly associated with a higher odds of FC $(1.45 ; 1.16-1.82)$ and death $(2.50 ; 1.93-3.25)$.

Participants in the low income category within each country had significantly higher odds of FC $(5.86$; 4.767.23) and death (5.52; 4.34-7.02) than participants with high income, relative to being alive and no FC. Using more extreme cut-offs for low and high household income $(0-50 \%$ of the mean national income for a low income and $>150 \%$ for a high income) resulted in higher odds of FC $(9.16 ; 7.07-11.87)$ and death $(9.30 ; 6.95-$ 12.44) for the low income category. The country-region specific analysis showed that a low income is especially a factor in predicting FC in the upper-middle income countries $(13.75 ; 10.21-18.51)$ and less so in lowermiddle income countries (1.97; 1.38-2.82) (Additional file 2: Table S2a and S2b). Not having paid work also increased the odds of FC (1.32; 1.11-1.56) and death (1.60; 1.31-1.94). Having some form of health insurance provided protection from FC; those without insurance were more likely to experience FC than those with insurance $(1.27 ; 1.05-1.52)$. Participants without health insurance were more likely to die $(1.51 ; 1.21-1.88)$, relative to being alive and not experiencing FC; health insurance was inversely related to $\mathrm{FC}$ in upper-middle income countries only.

Cancer stage IV at diagnosis was significantly associated with a higher odds of FC $(1.52 ; 1.12-2.05)$ and death $(5.43 ; 3.76-7.82)$, compared to stage I. In terms of health-related quality of life, a decrement of 0.1 point as assessed on the EQ-5D was associated with higher odds of FC $(1.11 ; 1.07-1.16)$ and death $(1.24 ; 1.18-1.30)$.

In females, cancer site was not associated with FC. In males, cancer in the head and neck region $(0.54$; $0.36-$ $0.80)$ and haematological cancers $(0.56 ; 0.42-0.76)$ were associated with a lower odds of FC compared to digestive cancers (reference group).

Sensitivity analyses employing missing value imputation (Additional file 2: Table S3) did not change the inferences, except that the effect of health insurance on the odds of FC became non-significant at the conventional $5 \%$ level.

\section{Discussion}

To our knowledge, the ACTION study is the largest observational study of the household burden of cancer yet conducted in Asia. A year after diagnosis, almost a third of patients affected by cancer in the ASEAN region died and almost a half of their households faced catastrophic health care expenses. Patients with advanced stages of cancer at diagnosis and socioeconomically disadvantaged cancer patients, including those with primary education only, low income, and no health insurance, were more likely to experience FC or die within 12 months. 
Table 1 Demographic, socioeconomic, and clinical characteristics of the study population $(n=9,513)$

\begin{tabular}{|c|}
\hline Characteristic \\
\hline Age (years) \\
\hline$<45$ \\
\hline $45-54$ \\
\hline $55-64$ \\
\hline$\geq 65$ \\
\hline Missing \\
\hline Sex \\
\hline Male \\
\hline Female \\
\hline Marital status \\
\hline Married \\
\hline Not married \\
\hline Missing \\
\hline Level of education \\
\hline 0-6 years (primary) \\
\hline $7-12$ years (secondary) \\
\hline$>12$ years (tertiary) \\
\hline Missing \\
\hline Country of residence \\
\hline Cambodia \\
\hline Indonesia \\
\hline Laos \\
\hline Malaysia \\
\hline Myanmar \\
\hline Philippines \\
\hline Thailand \\
\hline Vietnam \\
\hline Household size \\
\hline $1-2$ \\
\hline $3-5$ \\
\hline$>5$ \\
\hline Missing \\
\hline
\end{tabular}

Household income (of mean national income)

$$
\begin{aligned}
& \text { 0-25\% } \\
& 25-50 \% \\
& 50-75 \% \\
& 75-100 \% \\
& 100-125 \% \\
& 125-150 \% \\
& 150-175 \% \\
& 175-200 \% \\
& >200 \%
\end{aligned}
$$

n $\%$

$2,780 \quad 29$

$2,801 \quad 30$

$2,463 \quad 26$

$1,467 \quad 15$

$2<1$

$3,470 \quad 37$

$6,043 \quad 63$

$7,352 \quad 77$

$2,154 \quad 23$

$7<1$

$3,693 \quad 39$

$3,817 \quad 40$

$1,992 \quad 21$

$11<1$

$206 \quad 2$

$2,335 \quad 25$

1011

1,66218

$1,178 \quad 12$

$909 \quad 10$

$1,206 \quad 13$

$1,916 \quad 20$

$1,337 \quad 14$

$5,555 \quad 58$

$2,570 \quad 27$

$9<1$

$1,103 \quad 12$

$1,185 \quad 13$

$1,031 \quad 11$

$1,020 \quad 11$

$767 \quad 8$

$381 \quad 4$

$427 \quad 5$

$417 \quad 4$

$1,819 \quad 19$
Table 1 Demographic, socioeconomic, and clinical characteristics of the study population $(n=9,513)$ (Continued)

\begin{tabular}{lll}
\hline Not known & 1,336 & 14 \\
Missing & 27 & $<1$ \\
Main source of household income & & \\
Crops and agricultural sidelines & 1,965 & 21 \\
Family business & 1,287 & 14 \\
Wages & 4,568 & 48 \\
Remittances and gifts & 455 & 5 \\
Other income & 1,213 & 13 \\
Missing & 25 & $<1$
\end{tabular}

Health insurance status

Government-provided insurance -

Employment-based insurance $\quad 568 \quad 6$

Private insurance

$857 \quad 9$

Other community insurance $\quad 65<1$

None

$5,237 \quad 55$

Missing

$11<1$

Type of hospital

Public

8,76092

Private

6106

Other (for example, military)

1432

Experienced economic hardship in the year before diagnosis Yes

$5,146 \quad 54$

$4,352 \quad 46$

$15<1$

Missing

Paid work (patient level) before diagnosis (self-employed or for a wage)

Yes

$4,512 \quad 47$

No

$4,992 \quad 53$

Missing

$9<1$

Cancer site

$\begin{array}{lll}\text { Mouth and pharynx } & 1,063 \quad 11\end{array}$

Oesophagus $\quad 160 \quad 2$

Stomach

3053

Colon and rectum

$910 \quad 10$

Liver

831

Pancreas

$53<1$

Trachea, bronchus, and lung

$623 \quad 7$

Melanoma

$40<1$

Female breast

$2,445 \quad 26$

Cervix

$1,005 \quad 11$

$177 \quad 2$

$242 \quad 3$

$47<1$ 
Table 1 Demographic, socioeconomic, and clinical characteristics of the study population $(n=9,513)$ (Continued)

\begin{tabular}{lll}
\hline Bladder & 60 & $<1$ \\
Lymphomas and multiple myeloma & 454 & 5 \\
Leukaemia & 371 & 4 \\
Other malignant neoplasms & 1,295 & 14 \\
Missing & 179 & 2 \\
Cancer stage & & \\
Stage I & 590 & 6 \\
Stage II & 1,613 & 17 \\
Stage III & 1,696 & 18 \\
Stage IV & 1,260 & 13 \\
None (haematological cancers) & 825 & 9 \\
Missing & 3,529 & 37 \\
\hline
\end{tabular}

This research adds compelling evidence to the argument for effective cancer control policies and timely access to affordable treatment in low- and middle-income countries. Previously, evidence of significant household economic burden due to cancer has come from only a few, small cross-sectional studies [23, 24]. There has, however, been increasing attention given to the economic impact of non-communicable diseases in lowand middle-income settings, with two recent reviews

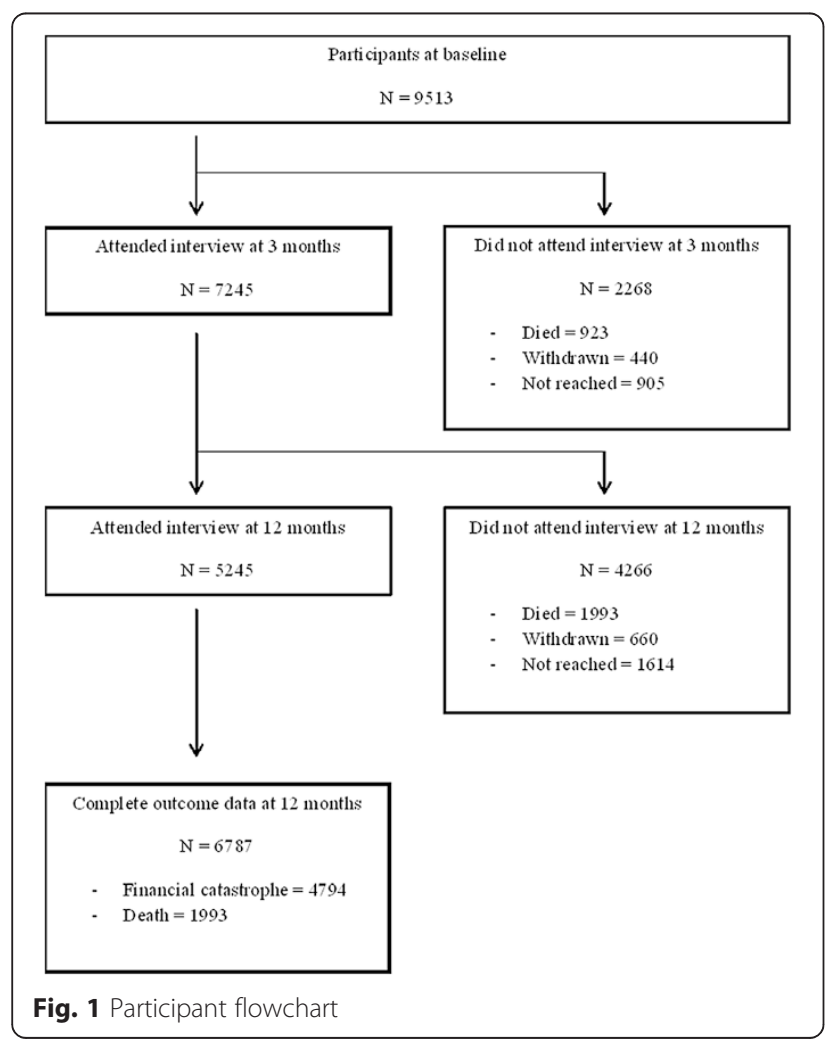

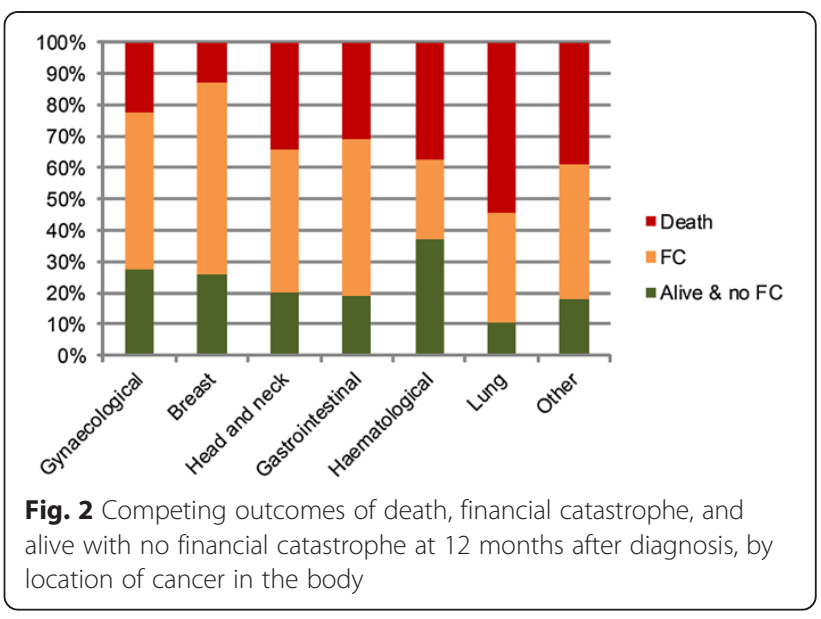

highlighting the heavy financial burden that such diseases pose on affected households [25, 26]. In a review of studies that reported on expenditures on chronic diseases, mean expenditures ranged from $5 \%$ to $59 \%$ of household income, household total health expenditure, and household non-food expenditure, but results on catastrophic health expenditures were not reported [26]. A literature review on the costs imposed by noncommunicable diseases in low- and middle-income settings included 19 studies that reported on OOP health expenditure as a percentage of capacity to pay or total household expenditure due to health shocks, and found that between $0 \%$ and $34 \%$ of the study population experienced FC, depending on the methods used [25]. Comparison of these findings with our results is difficult due to differences in defining catastrophic spending: some studies used a threshold OOP share of total household expenditure; others of household 'capacity to pay'; or of 'non-food expenditure'. In addition, the threshold used also varies, ranging from $10 \%$ to $40 \%$. Furthermore, in the majority of the above-mentioned studies, OOP estimates were based on retrospective recall of health care utilisation in household surveys, while our study used a prospective cost diary. Studies have shown that OOP estimates depend heavily on the measures used and length of recall periods $[27,28]$. Compared to prospective cost diaries, health care utilisation is generally under-reported in household surveys [27]. Nonetheless, results from this study, taken together with other studies, signal the potential for cancer to result in a significant economic burden.

Women were less likely to die in the year following a cancer diagnosis than men, but no significant association between the patient's sex and their household's odds of experiencing FC was found. Better survival rates for female cancers may be explained by the high proportion of breast cancer in this population, and its relatively good prognosis, while colorectal, mouth and lung cancers, with a generally poor prognosis [29], were most common in men. 
Table 2 Odds ratios (and $95 \%$ confidence intervals) for financial catastrophe and death, relative to no financial catastrophe (reference) in all participants with complete outcome data $(n=6,787)$, adjusted for age, sex, cancer stage, and geographic region

\begin{tabular}{|c|c|c|c|}
\hline Characteristic & & Financial catastrophe & Death \\
\hline \multirow[t]{4}{*}{ Age (years) } & $<45$ & Reference & Reference \\
\hline & $45-54$ & $1.05(0.85-1.30)$ & $1.08(0.84-1.38)$ \\
\hline & $55-64$ & $1.41(1.13-1.75)$ & $1.59(1.23-2.04)$ \\
\hline & $\geq 65$ & $1.51(1.17-1.94)$ & $2.64(2.00-3.49)$ \\
\hline \multirow[t]{2}{*}{ Sex } & Men & Reference & Reference \\
\hline & Women & $1.14(0.96-1.36)$ & $0.62(0.51-0.75)$ \\
\hline \multirow[t]{3}{*}{ Highest level of education } & Tertiary & Reference & Reference \\
\hline & Secondary & $1.44(1.16-1.79)$ & $1.43(1.11-1.85)$ \\
\hline & Primary & $1.45(1.16-1.82)$ & $2.50(1.93-3.25)$ \\
\hline \multirow[t]{2}{*}{ Marital status } & Married & Reference & Reference \\
\hline & Unmarried & $1.32(1.09-1.60)$ & $1.42(1.15-1.77)$ \\
\hline \multirow[t]{2}{*}{ Health insurance } & Yes & Reference & Reference \\
\hline & No & $1.27(1.05-1.52)$ & $1.51(1.21-1.88)$ \\
\hline \multirow[t]{2}{*}{ Economic hardship } & No & Reference & Reference \\
\hline & Yes & $1.40(1.19-1.64)$ & $1.82(1.51-2.20)$ \\
\hline \multirow[t]{3}{*}{ Income level } & High & Reference & Reference \\
\hline & Middle & $2.15(1.73-2.67)$ & $1.91(1.47-2.47)$ \\
\hline & Low & $5.86(4.76-7.23)$ & $5.52(4.34-7.02)$ \\
\hline \multirow[t]{2}{*}{ Paid work } & Yes & Reference & Reference \\
\hline & No & $1.32(1.11-1.56)$ & $1.60(1.31-1.94)$ \\
\hline \multirow[t]{7}{*}{ Cancer region: females } & Digestive/gastrointestinal & Reference & Reference \\
\hline & Breast & $0.99(0.69-1.41)$ & $0.45(0.29-0.69)$ \\
\hline & Gynaecological & $0.73(0.49-1.08)$ & $0.69(0.43-1.11)$ \\
\hline & Head and neck & $0.69(0.40-1.19)$ & $0.65(0.35-1.18)$ \\
\hline & Haematological/blood & $0.90(0.69-1.19)$ & $1.93(1.39-2.69)$ \\
\hline & Respiratory/thoracic & $1.36(0.65-2.85)$ & $2.28(1.07-4.86)$ \\
\hline & Other & $0.83(0.48-1.41)$ & $0.99(0.54-1.83)$ \\
\hline \multirow[t]{5}{*}{ Cancer region: males } & Digestive/gastrointestinal & Reference & Reference \\
\hline & Head and neck & $0.54(0.36-0.80)$ & $0.36(0.24-0.55)$ \\
\hline & Haematological/blood & $0.56(0.42-0.76)$ & $1.10(0.80-1.51)$ \\
\hline & Respiratory/thoracic & $1.18(0.67-2.09)$ & $1.88(1.07-3.31)$ \\
\hline & Other & $0.56(0.37-0.86)$ & $0.65(0.41-1.01)$ \\
\hline \multirow[t]{5}{*}{ Cancer stage } & I & Reference & Reference \\
\hline & $\|$ & $1.23(0.94-1.60)$ & $0.93(0.65-1.34)$ \\
\hline & III & $1.23(0.94-1.62)$ & $2.34(1.65-3.33)$ \\
\hline & IV & $1.52(1.12-2.05)$ & $5.43(3.77-7.82)$ \\
\hline & None (haematological cancers) & $0.68(0.49-0.95)$ & $3.04(2.07-4.46)$ \\
\hline EQ-5D score (per 0.1 decrement) & & $1.11(1.07-1.16)$ & $1.24(1.18-1.30)$ \\
\hline
\end{tabular}

The risk of FC increases with age, perhaps due to increasing co-morbidities which result in greater complexity of the illness and treatment. As expected, age was significantly associated with the risk of death at
12 months. A more advanced cancer stage at diagnosis was associated with higher odds of FC and death.

We found that having a below average income, no health insurance, not having paid work, having experienced 
economic hardship prior to diagnosis, and having experienced no more than primary education, were all associated with a higher odds of experiencing FC. Household income showed the strongest association, with these patients having more than five times the odds of FC when an income $<75 \%$ of the mean national income was considered a low income, and even nine times the odds when an income $<50 \%$ was used as the threshold. That this gradient was found to be more pronounced in upper-middle compared to lowermiddle income countries suggests that the risk of FC posed by having a low income is as much based on relative as opposed to absolute disadvantage.

The relationship between health insurance and FC found in the primary analyses of this study was not particularly strong, and was non-significant in the sensitivity analysis where missing data were imputed. Analyses by level of economic development provided some explanation to these inconclusive results: in upper-middle income countries (Malaysia and Thailand) health insurance did provide significant protection from FC; but in lowermiddle income countries it did not. This may be explained by the limitations of benefit packages available through health insurance programs in some of the participating lower-middle income countries, which has been wellrecognised as a problem in Vietnam and the Philippines [13]. Since health insurance status was assessed as a categorical variable it was not possible to take into account variations in level of coverage.

The findings in relation to the socioeconomic variables reinforce the well-founded conclusions that can be drawn from the social determinants literature - those at greater levels of disadvantage tend to have higher risks of financial hardship and poor health [30]. Reflecting this was the strong relationship of various socioeconomic indicators and death within 12 months. This, and the observed association between low quality of life and higher odds of FC, underscores the relationship between underlying economic disadvantage, health, and economic outcomes in cancer.

The study has a number of limitations. We did not recruit a random cross-section of people with incident cancer in the region due to a variety of reasons. First, as we could only identify cases once individuals presented to hospital, we potentially excluded individuals who did not seek hospital treatment due to geographical isolation, poverty, or socio-cultural barriers [31]. Second, clinicians responsible for enrolling patients into the study appear to have under-recruited those with the most virulent types of cancer, such as lung and liver cancers. Third, public awareness of some types of cancer, specifically breast cancer, was greater than for others, which is likely to have additionally motivated certain cancer patients, particularly women, to agree to participate in the study. Furthermore, patients treated in private hospitals were under-represented in the study (6\%) and it is unclear whether this has introduced a bias in our estimates of the level of FC. Although private hospitals have often been observed to generate the highest OOP expenses [25] they also tend to attract patients with a higher income. All these factors compromise the generalisability of some of our results, and probably means that we have underestimated the 12-month rate of death from all cancers, but is unlikely to invalidate the main conclusions. Another drawback is that 2,767 participants $(29 \%)$ lacked at least one component of data on death, household income, or OOP costs required to compute the study outcomes. The challenges of eliciting income and other socioeconomic data have been well-documented [32], and incomplete follow-up due to being unable to contact many subjects in rural areas, despite repeated telephone calls and field visits, is inevitable in the region studied. The findings from the sensitivity analysis, in which multiple imputation was used to impute the missing data, did not vary substantially from the non-imputed findings, and would not alter conclusions.

These drawbacks have to be considered in the light of the paucity of cancer statistics from the region sampled $[2,15,33]$. The study benefited from having a large sample of patients with various cancer sites and cancer stages from eight countries which have disparate health systems. Due to the large size of the study, it was possible to produce reliable estimates of the influence of a range of demographic, socioeconomic, and clinical predictors. In addition, the study's longitudinal approach improved on most previous economic studies which used cross-sectional surveys based on retrospective reporting of costs, as well as much smaller sample sizes, with subsequent jeopardy for both bias and sampling error. Furthermore, using a multinomial logistic regression model, we were able to adjust FC for the competing outcome of death. This is important as studies that have previously examined the burden to households associated with illnesses have generally focused exclusively on 'economic' outcomes in terms of OOP costs and FC [10, $25,26]$, but have overlooked a crucial reason why patients may avoid, or not report incurring, high OOP costs, that is, they may die, and this is unlikely to be non-informative censoring.

\section{Conclusions}

This study provides the type of precise evidence that is required to develop effective policies and programs to address the overall burden of cancer care in the ASEAN region, with potential generalisation elsewhere in the developing world. The results show that a cancer diagnosis is disastrous, even within only 12 months, for over $75 \%$ 
of new patients. Socioeconomically disadvantaged cancer patients and patients with advanced cancer stages at diagnosis were common and particularly vulnerable to adverse economic outcomes and poor survival. The need for more resources to aid early detection as well as policies that improve access to care, by removing financial barriers and providing adequate financial protection from the costs of illness, is clear.

\section{Key message}

Over 75 \% of new cancer patients in Southeast Asia experience financial catastrophe or die within one year. An advanced stage at diagnosis and socioeconomic disadvantage are significant risk factors for these poor outcomes. There is an urgent need for more resources to aid early detection and policies aimed to provide adequate financial protection from the costs of cancer.

\section{Appendix}

Writing committee

Merel Kimman ${ }^{1,2, *}$

Email: mkimman@georgeinstitute.org.au

Stephen $\operatorname{Jan}^{1}$

Cheng Har Yip ${ }^{3}$

Hasbullah Thabrany ${ }^{4}$

Sanne A Peters ${ }^{5}$

Nirmala Bhoo-Pathy ${ }^{6,7}$

Mark Woodward ${ }^{1,5, * *}$

Phone: +61299934514

Email: markw@georgeinstitute.org.au

${ }^{1}$ The George Institute for Global Health, University of Sydney, Level 10, King George V Building, 83-117 Missenden Road, Camperdown, NSW 2050, Australia

${ }^{2}$ Department of Clinical Epidemiology and Medical Technology Assessment, Maastricht University Medical Centre, Maastricht, the Netherlands

${ }^{3}$ Department of Surgery, University of Malaysia Medical Centre, Kuala Lumpur, Malaysia

${ }^{4}$ Center for Health Economics and Policy Studies, Universitas Indonesia, Jakarta, Indonesia

${ }^{5}$ The George Institute for Global Health, Nuffield Department of Population Health, University of Oxford, Oxford, UK

${ }^{6}$ National Clinical Research Centre, Ministry of Health, Kuala Lumpur, Malaysia

${ }^{7}$ Faculty of Medicine, University of Malaya, Kuala Lumpur, Malaysia

"Corresponding author. Department of Clinical Epidemiology and Medical Technology Assessment, Maastricht University Medical Centre, Maastricht, the Netherlands

"Corresponding author. The George Institute for Global Health, Nuffield Department of Population Health, University of Oxford, Oxford, UK

\section{Principal investigators}

Phetsamone Arounlangsy (Lao Cancer Center, Department of Health Care, Ministry of Health, Laos), Soe Aung (Oncology Society, Myanmar Medical Association, Yangon, Myanmar), Soledad L Balete (Section of Medical Oncology, Jose R Reyes Memorial Medical Centre, Manila, Philippines), Nirmala Bhoo-Pathy (National Clinical Research Centre, Ministry of Health, Malaysia; Faculty of Medicine, University of Malaya, Kuala Lumpur, Malaysia), Bounthaphany Bounxouei (Mahosot Hospital, Laos), Dieu Bui (K Hospital, Vietnam), Jay Datukan (Section of Medical Oncology, St Luke's Medical Centre, Quezon City, Metro Manila, Philippines), Agnes E Gorospe, (Section of Medical Oncology, St Luke's Medical Centre, Quezon City, Metro Manila, Philippines), Cheng Har Yip (University of Malaya, Kuala Lumpur, Malaysia), Prasit Khopaibul (Suratthani Cancer Centre, Suratthani, Thailand), Thanut Khuayjarernpanishk (Ubonratchathani Cancer Centre, Ubonratchathani, Thailand), Thiravud Khuhaprema (National Cancer Institute of Thailand, Bangkok, Thailand), Myo Khin (Department of Medical Research, Lower Myanmar, Myanmar), David Kingston, Tawin Klinwimol (Ubonratchathani Cancer Centre, Ubonratchathani, Thailand), Somkiet Lalitwongsa (Lampang Cancer Hospital, Lampang, Thailand), Dhanoo Lawbundis (Lopburi Cancer Hospital, Lopburi, Thailand), Conrado Lola (Section of Medical Oncology, National Kidney and Transplant Institute, Quezon City, Metro Manila, Philippines), Leo Marbella (Section of Medical Oncology, National Kidney and Transplant Institute, Quezon City, Metro Manila, Philippines), Khoa Mai Trong (Bach Mai Hospital, Vietnam), Soe Oo Maung (Department of Radiotherapy, Yangon General Hospital, Yangon, Myanmar), Shu Mon (Bahosi Hospital, Myanmar), Win Pa Pa Naing (Department of Medical Research, Lower Myanmar, Myanmar), Corazon A Ngelangel (Section of Medical Oncology, University of the Philippines - College of Medicine, Philippine General Hospital, Manila, Philippines), Htun Lwin Nyein (Haematology Department, Yangon General Hospital, Yangon, Myanmar), Annielyn Beryl Ong-Cornel (Veterans Memorial Medical Centre, Quezon City, Philippines), Khin May Oo (Department of Medical Research, Lower Myanmar, Myanmar), Irisyl Orolfo-Real (Section of Medical Oncology, University of the Philippines - College of Medicine, Philippine General Hospital, Manila, Philippines), Dung Pham Xuan (Oncology Hospital, Ho Chi Minh city, Vietnam), Seang Pharin (Department of Onco-Hematology, Calmette Hospital, Cambodia), Pujianto (Department of Health Policy and Administration, School of Public Health, Universitas Indonesia, Indonesia), Oudayvone Rattanavong (Mahosot Hospital, Laos), Kouy Samnang (Department of Oncology, Khmer-Soviet Friendship Hospital, Cambodia), Somphob Sangkittipaiboon (Lopburi Cancer Hospital, 
Lopburi, Thailand), Suleeporn Sangrajrang, (National Cancer Institute of Thailand, Bangkok, Thailand), Cherelina Santiago-Ferreras (Section of Medical Oncology, Veterans Memorial Medical Centre, Quezon City, Metro Manila, Philippines), San Shwe (Department of Medical Research, Lower Myanmar, Myanmar), Eav Sokha (National Cancer Centre, Calmette Hospital, Cambodia), Thanadej Sinthusake (Mahavajiralongkorn Thanyaburi Hospital, Pathumthani, Thailand), Darunee Suanplu (Suratthani Cancer Hospital, Suratthani, Thailand), Jitraporn Tanabodee (Chonburi Cancer Hospital, Chonburi, Thailand), Hasbullah Thabrany (Center for Health Economics and Policy Studies, Universitas Indonesia, Indonesia), Kitisak Thepsuwan (Chonburi Cancer Hospital, Chonburi, Thailand), Yin Yin Tun (Department of Medicine, No 2 Military Hospital, Myanmar), Heng Viroath (Department of Oncology, Khmer-Soviet Friendship Hospital, Cambodia), Le Le Win (Department of Medical Research, Lower Myanmar), Swe Swe Win (Department of Oral Medicine, University of Dental Medicine, Yangon, Myanmar), and Tin Moe Win (Mandalay General Hospital, Myanmar).

\section{Other contributors}

Ami Ashariati (Soetomo Hospital, Indonesia), Djumhana Atmakusuma (Cipto Mangunkusumo Hospital, Indonesia), I Made Bakta (Sanglah Hospital, Indonesia), Loan Dang Thi Kim (Oncology Hospital Ho Chi Minh city, Vietnam), Phung Dang Thi Ngoc (Oncology Hospital Ho Chi Minh city, Vietnam), Tuan Diep Bao (Oncology Hospital Ho Chi Minh city, Vietnam), Ario Djatmiko (Surabaya Oncology Hospital, Indonesia), Andi Fachruddin (Wahidin Hospital, Indonesia), Johan Kurnianda (Sardjito Hospital, Indonesia), Helen Monaghan (The George Institute for Global Health, Australia), Abdul Muthalib (Medistra Hospital, Indonesia), Trang Ngo Thuy (Bach Mai Hospital, Vietnam), Thao Nguyen Hoang, (K Hospital, Vietnam), Nga Nguyen Thi Hoai (K Hospital, Vietnam), Sonar S Panigoro (Dharmais Cancer Center Hospital, Indonesia), Huy Phạm Quang (K Hospital, Vietnam), Goh Pik Pin (National Clinical Research Centre, Malaysia), Khanh Quach Thanh (Oncology Hospital Ho Chi Minh city, Vietnam), Prih Sarnianto (Universitas Indonesia, Indonesia), Dradjat $\mathrm{R}$ Suardi (Hasan Sadikin Hospital, Indonesia), Shridevi Subramaniam (National Clinical Research Centre, Malaysia), Aru W Sudoyo (MRCCC Siloam Hospital, Indonesia), Khoa Tran Dang (Ha Noi Oncology Hospital, Vietnam), Ha Tran Dinh (Bach Mai Hospital, Vietnam), Catharina Suharti (Karyadi Hospital, Indonesia), and Suyatno (Adam Malik Hospital, Indonesia).

\section{Institutions}

CAMBODIA: Calmette Hospital (Phnom Penh) and Khmer-Soviet Friendship Hospital (Phnom Penh). INDONESIA: Adam Malik Hospital (Medan), Cipto Mangunkusumo Hospital (Jakarta), Dharmais Cancer
Center Hospital (Jakarta), Hasan Sadikin Hospital (Bandung), Karyadi Hospital (Semarang), Sanglah Hospital (Denpasar), Sardjito Hospital (Yogyakarta), Soetomo Hospital (Surabaya), Wahidin Sudirohusodo Hospital (Makassar), and Surabaya Oncology Hospital (Surabaya). LAOS: Mahosot Hospital (Vientiane). MALAYSIA: Hospital Ampang (Ampang), Hospital Kuala Lumpur (Kuala Lumpur), Hospital Melaka (Melaka), Hospital Queen Elizabeth I (Kota Kinabalu), Hospital Raja Perempuan Zainab II (Kota Baru), Hospital Seri Manjung (Seri Manjung), Hospital Sibu (Sibu), Hospital Sultanah Aminah (Johor Bahru), Hospital Sungai Buloh (Sungai Buloh), Hospital Tengku Ampuan Rahimah (Klang), Hospital Tuanku Fauziah (Kangar), Hospital Wanita dan Kanak-Kanak Sabah (Likas), Sime Darby Medical Centre (Subang Jaya), National Clinical Research Centre (Kuala Lumpur), University Malaya Medical Centre (Kuala Lumpur), and University Malaya Specialist Centre (Kuala Lumpur). MYANMAR: Bahosi Hospital (Yangon), Mandalay General Hospital (Mandalay), No 2 Military Hospital (Yangon), University of Dental Medicine (Yangon), and Yangon General Hospital (Yangon). PHILIPPINES: Jose R Reyes Memorial Medical Centre (Manila), University of the Philippines - College of Medicine Philippine General Hospital (Manila), National Kidney and Transplant Institute (Quezon City), St Luke's Medical Centre (Quezon City), and Veterans Memorial Medical Centre (Quezon City). THAILAND: Chonburi Cancer Hospital (Chonburi), Lampang Cancer Hospital (Lampang), National Cancer Institute of Thailand (Bangkok), Lopburi Cancer Hospital (Lopburi), Mahavajiralongkorn Thanyaburi Hospital (Pathumthani), Suratthani Cancer Centre (Suratthani), and Ubonratchathani Cancer Hospital (Ubonratchathani) VIETNAM: Bach Mai Hospital (Hanoi), K Hospital (Hanoi), and Oncology Hospital Ho Chi Minh city.

\section{Executive committee}

Nirmala Bhoo-Pathy, Bounthaphany Bounxouei, Gloria Cristal-Luna, Nguyen Chan Hung, Myo Khin, Thiravud Khuhaprema, Merel Kimman, David Kingston, Stephen Jan, Eav Sokha, Hasbullah Thabrany, and Mark Woodward.

\section{Secretariat}

Helen Monaghan, Merel Kimman, Stephen Jan, and Mark Woodward.

\section{Additional files}

Additional file 1: Overview approvals local ethics boards ACTION Study. (DOCX $14 \mathrm{~kb}$ )

Additional file 2: Table S1. Cancer stage by cancer site $(n=5,984)$. Cancer stage was not available for 3,529 participants. Table S2a. Odds ratios (and $95 \%$ confidence intervals) for financial catastrophe and death, 
relative to no financial catastrophe (reference) in participants from lower-middle income countries, adjusted for age, sex, cancer stage, and geographic region. Table S2b. Odds ratios (and $95 \%$ confidence intervals) for financial catastrophe and death, relative to no financial catastrophe (reference) in participants from upper-middle income countries, adjusted for age, sex, cancer stage, and geographic region. Table S3. Odds ratios (and $95 \%$ confidence intervals) for financial catastrophe and death, relative to no financial catastrophe (reference) in all participants ( $n=9,513)$, using missing value imputation and adjusted for age, sex, cancer stage, and geographic region. (DOCX $36 \mathrm{~kb}$ )

\section{Abbreviations}

ACTION: Asean CosTs In Oncology; ASEAN: Association of Southeast Asian Nations; Cl: Confidence interval; FC: Financial catastrophe; OOP: Out-of-pocket; OR: Odds ratio.

\section{Competing interests}

The authors declare that they have no conflicts of interest, other than the source of funding for this study.

\section{Authors' contributions}

Principal investigators assisted with the design of the questionnaires and were responsible for patient recruitment and data collection at participating sites. Other contributors assisted with data collection, patient interviews, and data entry. Contributions of members of the writing committee: MK, SJ, and MW designed the study; NBP, CHY, and HT collected data; MK wrote the first draft; and NBP, SJ, SP, HT, MW, and CHY made critical revisions to the manuscript. SP conducted the statistical analysis. All members approved the final manuscript.

\section{Acknowledgements}

This work was supported by an unrestricted educational grant from the Roche Asia Pacific Regional Office. The funder of the study had no role in study design, data analysis, data interpretation, or writing of this paper. Roche supported the data collection through recruitment of hospital sites and facilitating site investigator meetings. The authors had full access to all the data in the study and had final responsibility for the decision to submit for publication.

The authors wish to acknowledge the many patients and their family members who participated in this study, and physicians and other health personnel of participating sites. The Action Study Group comprises the writing committee, principal investigators and other contributors as detailed below.

\section{Writing committee}

Merel Kimman, Stephen Jan, Cheng Har Yip, Hasbullah Thabrany, Sanne A Peters, Nirmala Bhoo-Pathy, and Mark Woodward.

\section{Principal investigators}

Phetsamone Arounlangsy, Soe Aung, Soledad L Balete, Nirmala Bhoo-Pathy, Bounthaphany Bounxouei, Dieu Bui, Jay Datukan, Agnes E Gorospe, Cheng Har Yip, Prasit Khopaibul, Thanut Khuayjarernpanishk, Thiravud Khuhaprema, Myo Khin, David Kingston, Tawin Klinwimol, Somkiet Lalitwongsa, Dhanoo Lawbundis, Conrado Lola, Leo Marbella, Khoa Mai Trong, Soe Oo Maung, Shu Mon, Win Pa Pa Naing, Corazon A Ngelangel, Htun Lwin Nyein, Annielyn Beryl Ong-Cornel, Khin May Oo, Irisyl Orolfo-Real, Dung Pham Xuan, Seang Pharin, Pujianto, Oudayvone Rattanavong, Kouy Samnang, Somphob Sangkittipaiboon, Suleeporn Sangrajrang, Cherelina Santiago-Ferreras, San Shwe, Eav Sokha, Thanadej Sinthusake, Darunee Suanplu, Jitraporn Tanabodee, Hasbullah Thabrany, Kitisak Thepsuwan, Yin Yin Tun, Heng Viroath, Le Le Win, Swe Swe Win, and Tin Moe Win.

\section{Other contributors}

Ami Ashariati, Djumhana Atmakusuma, I Made Bakta, Loan Dang Thi Kim, Phung Dang Thi Ngoc, Tuan Diep Bao, Ario Djatmiko, Andi Fachruddin, Johan Kurnianda, Helen Monaghan, Abdul Muthalib, Trang Ngo Thuy, Thao Nguyen Hoang, Nga Nguyen Thi Hoai, Sonar S Panigoro, Huy Pham Quang, Goh Pik Pin, Khanh Quach Than, Prih Sarnianto, Dradjat R Suardi, Shridevi Subramaniam, Aru W Sudoyo, Khoa Tran Dang, Ha Tran Dinh, Catharina Suharti, and Suyatno.
Received: 2 June 2015 Accepted: 24 July 2015

Published online: 18 August 2015

\section{References}

1. Stewart BW, Wild CP, editors. World cancer report 2014. Lyon: International Agency for Research on Cancer; 2014.

2. Ferlay J, Soerjomataram I, Ervik M, Dikshit R, Eser S, Mathers C, et al. Cancer incidence and mortality worldwide: IARC CancerBase No. 11 [Internet]. GLOBOCAN 2012 v1.0. Lyon: International Agency for Research on Cancer; 2013.

3. Kimman M, Jan S, Monaghan H, Woodward M. The relationship between economic characteristics and health-related quality of life in newly diagnosed cancer patients in Southeast Asia: results from an observational study. Quality Life Res. 2014;24:937-49.

4. Pisani P, Parkin DM, Ferlay J. Estimates of the worldwide mortality from eighteen major cancers in 1985. Implications for prevention and projections of future burden. Int J Cancer. 1993;55:891-903.

5. Azzani M, Roslani AC, Su TT. The perceived cancer-related financial hardship among patients and their families: a systematic review. Supportive Care Cancer. 2014;23:889-98.

6. O'Donnell O, van Doorslaer E, Rannan-Eliya RP, Somanathan A, Adhikari SR, Akkazieva B, et al. Who pays for health care in Asia? J Health Econ. 2008:27:460-75.

7. Arrossi S, Matos E, Zengarini N, Roth B, Sankaranayananan R, Parkin M. The socio-economic impact of cervical cancer on patients and their families in Argentina, and its influence on radiotherapy compliance. Results from a cross-sectional study. Gynecol Oncol. 2007;105:335-40.

8. Hoang Lan N, Laohasiriwong W, Stewart JF, Tung ND, Coyte PC. Cost of treatment for breast cancer in central Vietnam. Global Health Action. 2013;6:18872.

9. Adedapo KS, Fadiji IO, Orunmuyi AT, Ejeh JE, Osifo BO. High default rate in thyroid cancer management in Ibadan, Nigeria: a need for health insurance. Afr J Med Med Sci. 2012;41:105-9.

10. Xu K, Evans DB, Kawabata K, Zeramdini R, Klavus J, Murray CJ. Household catastrophic health expenditure: a multicountry analysis. Lancet. 2003;362:111-7.

11. Bona K, Dussel V, Orellana L, Kang T, Geyer R, Feudtner C, et al. Economic impact of advanced pediatric cancer on families. J Pain Symptom Manage. 2014;47:594-603

12. Saw YM, Win KL, Shiao LW, Thandar MM, Amiya RM, Shibanuma A, et al. Taking stock of Myanmar's progress toward the health-related Millennium Development Goals: current roadblocks, paths ahead. Int J Equity Health. 2013;12:78.

13. Tangcharoensathien V, Patcharanarumol W, Ir P, Aljunid SM, Mukti AG, Akkhavong $\mathrm{K}$, et al. Health-financing reforms in southeast Asia: challenges in achieving universal coverage. Lancet. 2011;377:863-73.

14. Jan S, Kimman M, Kingston D, Woodward M. The socioeconomic burden of cancer in member countries of the Association of Southeast Asian Nations (ASEAN)-stakeholder meeting report. Asian Pac J Cancer Prev. 2012;13:407-9.

15. Woodward M. A consensus plan for action to improve access to cancer care in the association of Southeast Asian Nations (ASEAN) region. Asian Pac J Cancer Prev. 2014;15:8521-6.

16. Kimman M, Jan S, Kingston D, Monaghan $\mathrm{H}$, Sokha E, Thabrany $\mathrm{H}$, et al. Socioeconomic impact of cancer in member countries of the Association of Southeast Asian Nations (ASEAN): the ACTION study protocol. Asian Pac J Cancer Prev. 2012;13:421-5.

17. Essue BM, Li Q, Hackett ML, Keay L, lezzi B, Tran KD, et al. A multicenter prospective cohort study of quality of life and economic outcomes after cataract surgery in Vietnam: the VISIONARY study. Ophthalmology. 2014;121:2138-46.

18. EuroQol. A new facility for the measurement of health-related quality of life. Health Policy (Amsterdam, Netherlands). 1990;16:199-208.

19. Alvarez-Hernandez E, Pelaez-Ballestas I, Boonen A, Vazquez-Mellado J, Hernandez-Garduno A, Rivera FC, et al. Catastrophic health expenses and impoverishment of households of patients with rheumatoid arthritis. Reumatologia Clin. 2012;8:168-73.

20. Heeley E, Anderson CS, Huang Y, Jan S, Li Y, Liu M, et al. Role of health insurance in averting economic hardship in families after acute stroke in China. Stroke J Cerebral Circulation. 2009;40:2149-56.

21. Biesheuvel CJ, Vergouwe Y, Steyerberg EW, Grobbee DE, Moons KG. Polytomous logistic regression analysis could be applied more often in diagnostic research. J Clin Epidemiol. 2008;61:125-34. 
22. van Buuren S. Multiple imputation of discrete and continuous data by fully conditional specification. Stat Methods Med Res. 2007;16:219-42.

23. Zaidi $A A$, Ansari TZ, Khan A. The financial burden of cancer: estimates from patients undergoing cancer care in a tertiary care hospital. Int J Equity Health. 2012;11:60

24. Mahal A, Karan A, Fan VY, Engelgau M. The economic burden of cancers on Indian households. PLoS One. 2013;8:e71853.

25. Alam K, Mahal A. Economic impacts of health shocks on households in low and middle income countries: a review of the literature. Globalization Health. 2014;10:21

26. Kankeu HT, Saksena P, Xu K, Evans DB. The financial burden from non-communicable diseases in low- and middle-income countries: a literature review. Health Res Policy Systems. 2013:11:31.

27. Ansah EK, Powell-Jackson T. Can we trust measures of healthcare utilization from household surveys? BMC Public Health. 2013;13:853.

28. Das J, Hammer J, Sánchez-Paramo C. The impact of recall periods on reported morbidity and health seeking behavior. J Develop Econ. 2012;98:76-88

29. Allemani C, Weir HK, Carreira H, Harewood R, Spika D, Wang XS, et al. Global surveillance of cancer survival 1995-2009: analysis of individual data for 25 676887 patients from 279 population-based registries in 67 countries (CONCORD-2). Lancet. 2014;85:977-1010

30. Wilkinson RG, Marmot MG. (Eds): Social determinants of health: the solid facts. 2nd ed. Geneva: World Health Organization; 2003.

31. Yip CH, Taib NA. Challenges in the management of breast cancer in low- and middle-income countries. Future Oncol. 2012;8:1575-83.

32. Turrell G. Income non-reporting: implications for health inequalities research. J Epidemiol Community Health. 2000;54:207-14.

33. Kimman M, Norman $R$, Jan $S$, Kingston D, Woodward M. The burden of cancer in member countries of the Association of Southeast Asian Nations (ASEAN). Asian Pac J Cancer Prev. 2012;13:411-20.

\section{Submit your next manuscript to BioMed Central and take full advantage of:}

- Convenient online submission

- Thorough peer review

- No space constraints or color figure charges

- Immediate publication on acceptance

- Inclusion in PubMed, CAS, Scopus and Google Scholar

- Research which is freely available for redistribution 